\title{
A CONSTITUIÇÃO DO SUJEITO PEDAGÓGICO SURDO: INVESTIMENTO COMUNITÁRIO NA ESCOLA
}

CDD: 371.912

\section{THE CONSTITUTION OF THE DEAF EDUCATIONAL SUBJECT: COMMUNITY SCHOOL INVESTMENT}

\author{
Liane Camatti ${ }^{1}$ \\ Márcia Lise Lunardi-Lazzarin ${ }^{2}$
}

\begin{abstract}
Resumo
Com o desenvolvimento deste artigo, pretende-se discutir a constituição do sujeito pedagógico surdo, a partir da convergência entre comunidade e escola de surdos. Trata-se de lançar um olhar para o sujeito objeto da pedagogia, que tem sua construção definida também pelas formas pelas quais a comunidade surda se insere no espaço da escola de surdos. O estudo que segue foi realizado utilizando, como sujeitos de pesquisa, surdos, alunos e professores de escolas específicas para surdos das cidades de Caxias do Sul/RS, Porto Alegre/RS e Santa Maria/RS. Para o desenvolvimento deste texto, foram utilizadas ferramentas analíticas advindas dos estudos de vertente pós-estruturalista, em função da conveniência que tal perspectiva apresenta, quando se põe como objetivo entender os processos de produção de verdades e de constituição de sujeitos. Foi possível traçar quatro estratégias centrais que ilustram o investimento por parte da comunidade na formação do sujeito político através da escola: a necessidade de manter o contato entre os pares surdos; a necessidade de atribuição de uma espacialidade geográfica e temporal às articulações comunitárias; a intervenção em idade precoce; e a presença de surdos com histórias pessoais e profissionais exitosas atuando na escola. Através do desenvolvimento deste artigo, foi possível perceber que a comunidade entende a escola como possibilidade de manutenção do seu funcionamento e de seus preceitos, em função de que o sujeito pedagogizado na escola aprende lá a ser político e a dar conta do que quer a comunidade.
\end{abstract}

Palavras-chave: Comunidade. Educação dos surdos. Escola.

\begin{abstract}
With the development of this article, we intend to discuss the constitution of the deaf pedagogic subject from the convergence between community and school for the deaf. It's take a look at the subject object of pedagogy that has its construction also defined by the ways in which the deaf community falls within the school for the deaf. The following study was conducted using as research subjects deaf students and teachers of specific schools for the deaf in the cities of the Caxias do Sul/ RS, Porto Alegre/RS and Santa Maria/RS. To develop this text, was used analytical tools resulting from studies of post-structuralist strand depending on the convenience of this perspective when it sets the objective to understand the processes of production of truth and the constitution of subjects. It was possible to outline four key strategies that illustrate the investment by the community in shaping the political subject through the school: the need to maintain contact with deaf peers; the need for allocation of a geographic and temporal spatiality to the joint community; the intervention at an early age; and the presence of deaf people with successful personal and professional stories working in the school. Through the development of this article, it was possible to realize that the community understands the school as a possibility of maintenance of its operation and principles according to which the subject who is pedagogized in the school learns there to be political and to account for what the community wants.
\end{abstract}

Keywords: Community. Education of the deaf. School.

\footnotetext{
1 Professora de LIBRAS da Universidade Federal do Pampa - Campus Uruguaiana. E-mail: lianecamatti@yahoo.com.br - Uraguaiana, Rio Grande do Sul, Brasil.

${ }^{2}$ Professora Adjunta do Programa de Pós-Graduação em Educação e do Departamento de Educação Especial da Universidade Federal de Santa Maria. E-mail: lunazza@gmail.com - Santa Maria, Rio Grande do Sul, Brasil.
} 
O discurso educativo moderno construiu um sujeito a partir de conjeturas específicas. Fendler (2000) colabora com esta discussão, ao abordar suposições ${ }^{3}$ que exemplificam a construção do sujeito educado ${ }^{4}$ : o sujeito tem capacidade para ser educado; a ascensão do sujeito ao conhecimento se dá por meio do saber científico; há um procedimento padrão, generalizável, para se chegar a ser educado, o que cria a possibilidade de abstrair o conhecimento e aperfeiçoá-lo através de métodos apropriados; o sujeito educado tem capacidade para reflexionar objetivamente e tem sido individualizado e identificado segundo referentes demográficos; ele é aquele que deseja educar-se e que quer ser autodisciplinado. Esse sujeito que, a partir de classificações educacionais, é produzido socialmente, historicamente e regulado, constitui-se em sujeito objeto da educação.

De qualquer forma, foi colada ao sujeito a necessidade de passar por regimes de escolarização a fim de tornar-se educado. A partir disso, é possível marcar que, neste artigo, o mote central se dá em torno da compreensão sobre o sujeito surdo que passa pela instituição escolar, com vistas a tornar-se "educado", autodisciplinado, agente de si mesmo. E aqui, este sujeito, objeto da pedagogia, também tem sua constituição definida pelos atravessamentos da comunidade surda no espaço escolar. Por isso, neste trabalho, o objeto de análise refere-se ao sujeito pedagógico surdo.

A partir disso, a problematização que norteia a produção deste estudo passa, principalmente, pela seguinte indagação: como se dá a produção do sujeito pedagógico surdo no espaço de intersecção entre escola e comunidade surda? Para fazer essa abordagem, este trabalho parte da materialidade obtida em discussões produzidas com surdos, professores e alunos, membros atuantes na comunidade e na escola de surdos de diferentes cidades do Rio Grande do Sul: Caxias do Sul, Porto Alegre e Santa Maria, que possuem escolas específicas para surdos, com grande representatividade entre os membros da comunidade; e, a partir disso, entende-se que as formas pelas quais a comunidade surda se insere na escola produzem formas específicas de disciplinamento e prescrevem constituições interessadas de formas de ser surdo.

Nesse contexto, as ferramentas analíticas utilizadas para o desenvolvimento deste texto são retiradas dos estudos de vertente pós-estruturalista, em função das possibilidades oferecidas por essa perspectiva teórica para a compreensão dos processos de produção de

\footnotetext{
${ }^{3}$ Aqui, utilizam-se apenas pontuações das suposições feitas pela autora a respeito da construção do sujeito educado. No texto completo, é possível encontrar uma genealogia desse sujeito, analisando a sua construção desde que tomado por Platão, passando por Tomas de Aquino e Descartes, até as recentes pedagogias educativas. ${ }^{4}$ Sujeito educado está sendo entendido aqui como o sujeito objeto da educação.
} 
verdades e de constituição de sujeitos. Esse empreendimento, então, é feito a partir da compreensão de que a comunidade se insere na escola com o objetivo de investir nela e de produzir, pelos processos de pedagogização escolar, formas específicas de ser surdo.

\section{A COMPOSIÇÃO DO CENÁRIO: COMUNIDADE E ESCOLA DE SURDOS}

A configuração do presente, classificada como pós-modernidade, modernidade líquida ou Contemporaneidade, deve, ainda que minimamente, ser considerada durante as abordagens acerca da comunidade. Não se põe como preocupação melhor nomear este presente ou argumentar exaustivamente sobre seus contornos; o que importa aqui é considerar que a configuração política deste início de século XXI afeta diretamente os modos de operar da comunidade. Como um fenômeno, "[...] o comunitarismo é uma reação esperável à acelerada 'liquefação' da vida moderna" (BAUMAN, 2001, p. 195). Pode-se dizer que as comunidades deste tempo entram em jogos, modificam suas estruturas e buscam novas estratégias, para que não sejam perdidas as suas forças e não se desvaneçam suas fronteiras.

A partir desse contexto, é possível falar sobre os contornos da estrutura da comunidade. Falar em estrutura comunitária não parece ser condizente com a perspectiva na qual se inscreve este estudo. No entanto, é possível esclarecer que a estrutura referida não é determinada a priori, mas constituída na história, sempre móvel e contingente. O que se intenta não é dizer que a estabilidade da comunidade foi rompida pela fluidez deste tempo. Ela pode ser tomada como uma (des)estabilidade que sempre esteve em movimento. Entretanto, neste momento, a comunidade surda, como qualquer outra formação comunitária, tem determinados contornos que se fazem necessários pelo contexto político.

A partir daí, abre-se uma interface desta discussão, que recai sobre os processos culturais envolvidos em tal dinâmica. Não haveria como evitar essa abordagem, uma vez que a comunidade surda se articula, sobretudo, em torno de toda uma retórica sobre sua cultura. Fazendo as vezes (também) de argumento, os artefatos culturais assumem o papel de norteadores do sentimento comum que move uma comunidade. Em outras palavras, como é recorrente nas falas dos sujeitos dessa comunidade, os surdos reúnem-se porque compartilham da mesma cultura. O objetivo de cada um desses sujeitos passa a ser "viver a cultura" com liberdade, sem repressão ou opressão. A possibilidade de isso acontecer efetivamente renderia um estudo ainda maior do que este, mas importa agora problematizar de que modo isso sustenta a comunidade, a partir do regime de verdade que se forma. 
Tal contribuição é fundamental, para desnaturalizar alguns dos discursos mais prevalentes no cenário atual da educação de surdos, que colocam a escola específica para esses sujeitos como o ápice das coisas que podem ser boas para uma comunidade que mantém uma retórica em torno de seus artefatos diferenciais. Estes, por sua vez, também são tomados de forma naturalizada. "[...] o termo cultura surda é usado como estratégia pela política da diferença e tem sido tão difundido que muitas vezes cai no engessamento" (GOMES, 2009, p. 8). Seguindo o empréstimo dessa autora, ao fazer isso, “[...] perde ideia da experiência de pertencer ao povo surdo e de suas múltiplas formas de acontecimento e recai ao nomenclaturá-la e enclausurá-la a partir de artefatos” (GOMES, 2009, p. 8).

A intenção, nesse momento, é de situar tais discursos em um campo permeado por forças que produzem, valoram e determinam as condições dos sujeitos surdos de estar no mundo. A significação da diferença se dá nesse campo conflituoso de forças que envolve culturas e relações indissociáveis de poder e de saber. A produção da alteridade, nesse contexto, passa inevitavelmente por relações de atribuição de sentido - sentido que também inexiste fora de campos de força de saber e de poder.

\footnotetext{
Pensar na existência de uma coisa-em-si equivale a pensar na existência de um mundo subtraído ao processo de atribuição de sentido. A coisa-em-si só poderia ser, então, um sem-sentido ou um sentido-fixo. Mas em qualquer ato de apresentação da coisa-em-si, que aponta para a relação entre forças que colocou em movimento esse pôr e esse posicionar da coisa-em-si. A coisa-em-si está inseparavelmente amarrada ao sentido (SILVA, 2002, p. 45).
}

É partindo desses entendimentos que se segue a discussão da produção do sujeito pedagógico surdo no espaço de intersecção entre comunidade e escola de surdos. Trata-se de um espaço que pode ser, entre outras coisas, o lugar do sentimento de conforto comunitário, podendo ser também o não-lugar ao qual é relegado o sujeito surdo a partir de técnicas de dominação, normalização e subjetivação.

\section{INSERÇÃO DA COMUNIDADE NA ESCOLA DE SURDOS: INVESTIMENTOS PARA CONSTITUIÇÃO DO SUJEITO PEDAGÓGOGICO SURDO}

Direto ao fim. O instrumento de direcionamento de relatos que foi produzido para esta pesquisa finalizava as discussões levantando a possibilidade do fechamento das escolas de surdos por força de lei. Esta seção analítica inicia com os relatos produzidos a partir dessa questão. 
Com isso, os surdos mais velhos, que tiveram a experiência da organização da escola e da comunidade, iriam ficando mais velhos, se engajando nas suas atividades, e os mais novos já iriam estudar diretamente nas escolas inclusivas. A organização da comunidade iria também se dissipando, em função de que estes, por desde sempre estarem nas escolas inclusivas, acabariam não participando em momento algum dessas discussões sobre questões específicas da surdez. Como isso não iria fazer parte das suas vidas desde sempre, acho que não lutariam por isso e que as articulações da comunidade seriam muito enfraquecidas (Aluno - Caxias do Sul).

Acho que os surdos não estudariam mais, ficariam pelas ruas, alguns iriam trabalhar em fábricas (Professor - Caxias do Sul).

Tomara que não fechem! Aqui em Caxias seria muito complicado, pois existe somente esta escola. Além disso, os instrutores trabalhariam onde? Eu conto que todos da escola, da comunidade, os familiares irão seguir lutando para que as escolas de surdos se mantenham. Acredito que o fechamento não iria acontecer (Professor - Caxias do Sul).

Difícil! Acho que iria diminuir substancialmente, até praticamente cessar a participação dos surdos nas escolas. Penso que estes não teriam vontade de continuar estudando e iriam diretamente procurar trabalhos mais simples, sem passar por formação acadêmica (Professor - Santa Maria).

Se as escolas de surdos fechassem, os surdos poderiam ir todos estudar na comunidade! (Professor - Santa Maria).

O objetivo de iniciar esta seção com esses excertos é evidenciar que o fechamento das escolas vem diretamente relacionado com o fim das articulações da comunidade. A partir daí, é possível proceder às análises que parecem compor o "resultado" mais interessante desta pesquisa e que encontram a pergunta central estabelecida no início deste trabalho. Trata-se de procurar as formas pelas quais a comunidade surda investe na escola de surdos, no sentido de garantir a continuidade e a força da própria comunidade. E como faz isso? Imprimindo no sujeito pedagogizado pela escola o espírito comunitário, regulando-o também pelos acordos que servem à comunidade surda. Basicamente, o que segue neste capítulo é a tentativa de mostrar esse movimento de investimento por parte da comunidade na formação do surdo politizado através da escola. A pretensão é a de evidenciar o modo como a comunidade surda procura, através da escola de surdos, formar nestes o espírito da comunidade, um sentimento de dever comum (ESPÓSITO, 2009) ou de mesma intencionalidade (BAUMAN, 2003).

Abrindo um breve parêntese, surge um espaço para pensar que Foucault, mesmo mantendo a educação como coadjuvante nas suas pesquisas, abriu um vasto campo de possibilidades de articular às interfaces educacionais as ferramentas que ele sugeriu. Isso ocorreu em razão da incidência que o processo educacional tem na constituição de sujeitos, o que possibilita, em termos, essa intersecção e abre a educação para um olhar a partir de 
Foucault. Considerando suas contribuições, Gadelha (2009, p. 173) propõe pensar no sujeito tomado como construção histórica; faz-se oportuno conceber que este tem na educação possibilidades de envolver-se em processos de "constituição de identidades, de personalidades, de formas de sensibilidade, de maneiras de agir, sentir e pensar, normalizadas, sujeitas, regulamentadas, controladas $[\ldots .$.$] ".$

Esse processo de constituição de sujeitos através da educação e a consequente pedagogização de quem passa pela escola remetem - entre outras coisas - às possibilidades que a comunidade surda tem encontrado, através da sua escola, de investir no corpo-orgânico de cada membro da comunidade. A escola foi criada pela comunidade e é sustentada por ela, uma vez que, através da constituição dos perfis políticos, a comunidade pode manter-se e assegurar-se.

A comunidade tem líderes, isso é óbvio. Historicamente, esses líderes são pessoas que têm muita força dentro da comunidade, que garantiram questões importantes, sobretudo, a língua de sinais. E isso sempre fez parte da resistência da comunidade. $O$ surgimento da escola, nesse sentido, teve uma importância ímpar, principalmente por ser um espaço que possibilita o trabalho curricular com questões que, historicamente, constituíram as comunidades: a sua história, as identidades, os movimentos surdos, etc. Isso possibilita a resistência da comunidade a partir do momento em que esse aluno, que aprende essas questões na escola, participa da comunidade com mais força, politizado, e devolve mais poder à comunidade (Professor - Santa Maria).

Também há a contribuição da presença constante, na escola de surdos, do presidente da Associação, que faz toda a divulgação de questões referentes à comunidade, faz o elo entre a Associação e a direção da escola. Dessa forma, o objetivo da gestão da Associação é que ela não fique de portas fechadas. Através desse contato, é possível trazer os familiares e também as crianças surdas para o espaço da Associação, podendo estes, desse modo, participar das discussões que lá são realizadas, com a presença de intérpretes. Esse movimento acaba por possibilitar a reunião de todos que apoiam a causa surda. E esse "arrebanhamento" é facilitado quando acontece na escola de surdos (Aluno - Santa Maria).

Há uma grande pressão em relação ao aprendizado da língua portuguesa e, em geral, essas pessoas julgam que a escola de surdos é fraca, acabam deixando, inclusive, de participar da comunidade surda. Outro problema é a língua de sinais, que, nesse contexto, "existe" para apenas um surdo. Irão faltar para ele questões como poesia, teatro, história dos surdos, elementos da educação de surdos, etc. Nada disso está contemplado no currículo, apenas a língua de sinais, que não dá conta do restante das questões que citei (Professor - Santa Maria).

A partir disso, evidencia-se que a escola é um meio legítimo de manutenção da comunidade. Para auxiliar nessa discussão, é interessante pensar na forma como as comunidades vêm surgindo como "alvo" de estratégias de governo. A ordem global prevalente neste século XXI, com seus preceitos políticos, econômicos e informacionais, demanda outras condições possibilitadoras do governo e da ordem social. As estratégias 
compreendem esferas diversas, e a funcionalidade das comunidades vem sendo oportunamente direcionada para isso. As comunidades, assim, entram no jogo tático do governo, tornando-se um filão interessante de investimento. $\mathrm{O}$ espírito criado em cada um que se identifica com a comunidade faz com que ele trabalhe por ela, com fidelidade tal que governar por meio de tecnologias de moralização através da comunidade se tornou, talvez, um caminho mais curto para a manutenção da ordem.

Talvez seja possível fazer um paralelo e pensar na própria fidelidade que a comunidade surda possui. Nesse sentido, da mesma forma, seguindo no intuito de evidenciar como a escola é tomada como o espaço que sela os laços de fidelização, há uma relação entre não passar pela escola de surdos e não conseguir adquirir o espírito comunitário.

\begin{abstract}
Mas, sobre participar na comunidade surda, os poucos casos que conheço [de surdos que estudam em escolas inclusivas] fazem a opção de não interagir com a comunidade. Não sei se por não se sentir bem, se por opção da família. Mas, caso haja algum surdo incluído, a comunidade o receberá e o convidará, especialmente mostrando a escola de surdos e tentando convencê-lo a estudar lá. Frequentemente, em encontros promovidos pela Associação, surdos de outras cidades, oriundos de escolas inclusivas, são recebidos pela nossa comunidade. É tranquilo, mas é possível perceber que seus desenvolvimentos linguístico e identitário são diferentes; eles ficam um pouco aquém dos surdos oriundos das escolas de surdos (Professor Santa Maria).
\end{abstract}

Alguns surdos optam pela inclusão, e eu respeito essa escolha deles. Por outro lado, temos a escola de surdos, na qual os atravessamentos identitários, culturais, de direitos, pessoais, ensino específico para os surdos, etc. estão presentes. Mas e na inclusão? Como fazer? O que tem nesses espaços? Ali há problemas de comunicação, de entendimento, uma preocupação exacerbada com as palavras em Língua Portuguesa, palavras essas que não têm significado algum para os surdos, etc. (Professor - Santa Maria).

Os surdos que estão nas escolas inclusivas podem não desenvolver noções acerca da cultura surda, acabam não conhecendo propostas, leis, etc., ou seja, não se reconhecem como surdos atuantes. Estão lá, aprendendo os conteúdos, mas perdem muito nesse outro lado (Aluno - Caxias do Sul).

É possível identificar que a escola serve à comunidade no sentido de conseguir, de certa forma, perpetuar o espírito político que precisa ter uma comunidade. É interessante apreciar que, por anos, pertencer à comunidade, ou seja, ter a identidade surda aceitável por ela, significava ser surdo, usuário da língua de sinais, simpatizante com as lutas da comunidade. Hoje, pelas diretrizes das políticas nacionais, isso parece não mais ser o bastante. Há uma necessidade constante de não permitir que a comunidade sucumba ou que se percam todos os elementos conquistados por ela, durante anos de articulações políticas. 
Nesse contexto, saber e dominar a língua de sinais já não é mais o bastante; é preciso defendê-la, militar por ela. Ter uma identidade atravessada pelos elementos culturais surdos já não é mais o bastante; é preciso ter $a$ identidade surda.

Tais movimentos podem ser colocados em ação justamente a partir da escola. $\mathrm{O}$ sujeito pedagógico, ou seja, o sujeito subjetivado e regulado pelas práticas da escola deve, dentre outros tantos perfis, atender à necessidade de ser político. Em outras palavras, a convergência da comunidade surda com o espaço da escola de surdos imprime, basicamente, um investimento na formação do surdo politizado.

Neste momento, a partir da materialidade produzida para esta pesquisa, é possível traçar quatro estratégias centrais que ilustram o investimento por parte da comunidade na formação do sujeito político através da escola. Esta análise aborda quatro questões: a necessidade de manter o contato entre os pares surdos; a necessidade de atribuição de uma espacialidade geográfica e temporal às articulações comunitárias; a intervenção em idade precoce; e a presença de surdos com histórias pessoais e profissionais exitosas atuando na escola.

Para iniciar, um dos argumentos que há muito faz parte da pauta das discussões políticas em relação à educação de surdos é justamente a necessidade de manter a possibilidade de contato dos surdos mais jovens com os mais antigos. Essa identificação, esse convívio com os pares leva a duas possibilidades de entendimento: a primeira delas é a de ver funcionar uma lógica de "aprendizado" e de exercício político.

A presença dos instrutores muitas vezes substitui até mesmo os pais dos alunos. Eles servem como fonte de informações, de aconselhamento para os surdos sobre questões de vida pessoal, sobre fatos que ocorrem fora do ambiente escolar. Se não houvesse essa figura, seria muito pior (Aluno - Caxias do Sul).

Eu acho importante a presença desses surdos na escola de surdos em função de que, mantendo apenas os ouvintes, os surdos acabam criando uma dependência desses ouvintes, e isso não é bom. É necessário que os surdos ocupem esses espaços, estejam ocupando posições importantes dentro das escolas, como profissionais, gestores, enfim, rompendo com a tutela que os ouvintes podem manter em relação aos surdos, caso essas posições sejam sempre ocupadas por ouvintes (Aluno - Santa Maria).

Os alunos que frequentam têm idades, desde pequenos (com um ano e meio já há crianças que vêm conviver com os surdos aqui), até alunos com idade mais avançada. A escola possui dois objetivos, ou melhor, dois caminhos de formação dos alunos. Há, por um lado, a formação científica, nas disciplinas como geografia, história, etc. Também há disciplinas sobre cultura surda e de língua de sinais. Por outro lado, há o fato de que os alunos estão permanentemente em contato com 
outras pessoas de mais idade ou com os próprios instrutores, com os quais podem aprender com suas experiências de vida, observar a forma como suas vidas se desenvolvem e até mesmo os seus problemas gerais, problemas familiares, etc. $O$ contato e observação cotidiana promovem a formação dos alunos nesse sentido (Professor - Caxias do Sul).

Essa relação de identificação dentro da escola acontece entre alunos e professores surdos. É possível observar que essa relação é diferente no caso dos professores ouvintes, que se preocupam mais especificamente com o ensino dos conteúdos, da Língua Portuguesa. Dessa forma, na escola de surdos, pela presença dos surdos, é possível ter a língua de sinais pura, com uso constante, servindo de modelo para os alunos. Estes já criam expectativas positivas em relação ao seu futuro (Professor Santa Maria).

Além disso, reforçar a necessidade de manutenção da reunião espacial e temporal dos surdos remete a outra possibilidade. A leitura imperativa aqui é sobre o fato de que comunidades não geográficas, como as comunidades gays, as de motivos religiosos, as pessoas com algum tipo de deficiência, são comunidades sem ligações espaciais ou temporais: "só existem na medida em que seus componentes sejam ligados através de identificações construídas em espaços não-geográficos de discursos ativistas, produtos culturais e imagens da mídia" (ROSE, 1996, p. 333). Assim sendo, a escola de surdos desponta não apenas como a oportunidade para que os surdos tenham acesso ao conhecimento na sua língua e sejam imersos em elementos da sua cultura. Além disso, e talvez estrategicamente, a comunidade surda encontra na escola a possibilidade de "ter um corpo".

A comunidade surda precisaria se articular na Associação [caso não houvesse escola para surdos]. Os surdos poderiam ir estudar em escolas regulares e, para os casos em que houvesse muita dificuldade na compreensão dos conteúdos, a Associação poderia prover profissionais para dar esse apoio aos estudantes surdos que não teriam mais a opção de estudar nas escolas de surdos. Isso garantiria a continuidade do que há de positivo no processo de aprendizagem dos surdos, não deixando esmaecer (Aluno - Santa Maria).

Em outras palavras, atribuir uma espacialidade e uma cronologia específica para o corpo comunitário é interessante, sobretudo, por favorecer o ativismo comunitário. A comunidade é necessária e demanda que seus membros carreguem a responsabilidade por ela até o final (ESPOSITO, 2009). Nesse sentido, o governo aqui se dá através da regulação de compromissos, energias e escolhas individuais (ROSE, 1996), e a escola de surdos parece ser o lócus privilegiado para que as regulações incidam nos sujeitos surdos.

A terceira estratégia identificada diz respeito à época da vida dos surdos em que é necessário iniciar a intervenção. Antes de olhar para a forma como isso opera no âmbito 
comunitário, cabe destacar que a escola atua como fonte de normalização também pelos propósitos da comunidade. O surdo da norma é aproximado ou afastado da média na medida em que tem ou não identidade, é ou não engajado. O jogo da norma, dentro da comunidade, passa a ser o da prevenção. A escola de surdos não está aí simplesmente, ela investe na vida desse surdo desde pequeno.

Para crianças surdas, em função de todos esses elementos: língua, cultura, identidade, o melhor local é mesmo a escola de surdos. Não apenas pela presença dos professores surdos, mas pelo ambiente como um todo, que valoriza a experiência visual, o contato com os surdos adultos, com a língua de sinais, etc. Nas cidades pequenas, é possível organizar os surdos em classes separadas, mas garantindo o contato entre eles. Nas grandes cidades, é necessário ter escolas específicas para surdos, pois isso garante a possibilidade de os surdos resistirem e garantirem algumas coisas (Professor - Santa Maria).

Para crianças pequenas, primeiramente, a escola de surdos, porque não é possível receber uma criança surda em uma escola, calcar em conteúdos e no ensino pesado, também levar às terapias fonoaudiológicas, às clínicas, etc., e essa criança fica "pipocando" por diferentes espaços. O melhor é mesmo trazer para a escola de surdos, porque, no processo que expliquei anteriormente, a criança já constrói sua identidade de forma confusa, sem muita clareza se é surdo ou se é ouvinte, sempre em um meio termo. Aqui na escola de surdos, todos se empenham em construir na criança a ideia de que é surda e, assim, constituir a sua identidade surda (Professor - Santa Maria).

Acho que não resolve o problema não [a inserção da língua de sinais nos contextos das escolas regulares]. Com surdos maiores, pode até ser que se consiga algum resultado, mas, com crianças pequenas, isso seria impossível. Como aconteceria a organização identitária dos surdos? Com mais idade, tudo bem, mas sabemos de vários casos de surdos que saem da escola de surdos e optam pela inclusão, acabam experimentando o fracasso e retornam para a escola de surdos (Professor - Caxias do Sul).

Pela minha experiência, frequentar a escola de ouvintes e manter apenas sinais caseiros me possibilitava uma comunicação mais limitada. Ao entrar em contato com mais surdos, o desenvolvimento da minha língua foi mais rápido e completo. Eu penso que, no mínimo, até a quinta série os surdos precisam estudar na escola de surdos. Nesse período é que ele irá constituir a sua língua e identidade; depois, até pode ir para a inclusão. Antes da quinta série, é impossível (Professor - Porto Alegre).

Na verdade, eu penso que até a oitava série se precisa garantir que o surdo fique na escola de surdos. No ensino médio, pode mudar de escola, até porque precisa preparar-se para o vestibular (Professor - Porto Alegre).

Se for necessário investir na regulação desse surdo, a escola é, aparentemente, um local privilegiado para isso, em função dos processos que lhe são inerentes - a pedagogização dos sujeitos que por ela passam. Além disso, tal argumento tem maior abrangência a partir da ênfase, como visto nos excertos, de que o melhor local para os surdos pequenos é a escola de surdos. 
Outro elemento também trazido pelos surdos é o momento da vida desses sujeitos em que não mais seria preciso frequentar a escola de surdos. Em geral, isso coincide com a idade cronológica na qual a língua de sinais (elemento cognitivo e cultural) já estaria estruturada e a identidade surda (elemento identitário), constituída. Esse tempo refere-se justamente a quando o perfil político já está devidamente formado.

Para dar conta das demandas da comunidade, é necessário que a escola ofereça, na sua própria estrutura, as ferramentas que possibilitem a construção desse sujeito que quer a comunidade. Para isso, surge a quarta estratégia apontada nesta análise: a crescente participação de experiências exitosas na escola.

\footnotetext{
Vêm aumentando as possibilidades de os surdos estarem nesses espaços, em função de que os jovens estão se formando como alunos, buscando formações superiores e podendo retornar à escola como profissionais. Antes era mais complicado, pois os surdos de mais idade já estavam atuando em outras frentes, mas agora as possibilidades aumentaram. Além disso, é preciso encorajar os surdos no sentido de que eles podem fazer isso. É um processo (Aluno - Caxias do Sul).
}

Aqui na escola, temos um surdo que ocupa a vice-direção da escola. Além de tudo isso que já foi dito, esse fato tem uma importância por servir como modelo para as crianças surdas. Estas, muitas vezes, ficam um pouco desacreditadas em relação ao seu futuro. Com a possibilidade de ter referências, essas perspectivas melhoram para as crianças. Hoje, aqui na escola, já temos profissionais das carreiras de Psicologia, Educação Física, acadêmicos de Letras/Libras, vice-diretor, funcionários, enfim, uma série de profissionais surdos que servem de referência e que criam melhores expectativas nas crianças surdas em relação ao seu futuro. Criado esse sentimento, já não mais importará o espaço geográfico em que o surdo estiver, pois estará consigo essa expectativa (Aluno - Santa Maria).

É muito importante que haja professores, educadores e instrutores surdos ocupando posições importantes na escola, pois os alunos irão tê-los como modelos e conceber que possuem capacidade para chegar às mesmas posições. Isso impulsiona a busca dos alunos pela questão profissional (Professor - Caxias do Sul).

A criança, assim, desde pequena, vê e acredita que é possível chegar lá. Isso cria dois movimentos: por um lado, a possibilidade de que os surdos façam a opção pela escola e, por outro, o êxito da estratégia comunitária de continuar tendo as condições necessárias para investir e formar politicamente os sujeitos. Nessa mesma lógica, como sabido e já evidenciado pelos excertos neste artigo, a comunidade muitas vezes nega com veemência a possibilidade de os surdos estudarem em escolas inclusivas. Isso pode ser lido como uma forma de evitar que os surdos vão para a escola de ouvintes e que possam "beber" do que vem dos ouvintes e contaminar a pretensa pureza da comunidade surda. 


\section{FALAR OU NÃO FALAR EM RESULTADOS?}

Ao assumir a contingência na qual se produzem tanto escola e comunidade surda quanto o sujeito surdo que foi aqui abordado, parece ser incoerente fixar formas específicas de constituição de sujeitos pedagógicos surdos a partir da convergência entre comunidade e escola de surdos. No entanto, faz-se aqui uma tentativa de compreender os elementos que constituem o cenário em questão e que têm como fulcro o questionamento estabelecido no início desta pesquisa: como se dá a produção do sujeito pedagógico surdo no espaço de intersecção entre escola e comunidade surda?

Possivelmente, a análise feita neste texto auxilia a pensar como, nesse momento político, ocorre essa intersecção e de que forma, a partir disso, são impressas nos sujeitos pedagogizados pelo espaço escolar formas específicas de ser surdo. Esta pesquisa e os quatro elementos táticos abordados que tornam possível que a comunidade invista no sujeito surdo por meio da escola parecem não necessariamente responder, mas circunscrever as possibilidades de resposta para as questões: o que quer a comunidade ao defender a escola de surdos? O que ela ganha com isso? Essa intersecção entre escola e comunidade parece estar muito mais na ordem do político do que na esfera de construção de conhecimentos.

A partir disso, é possível voltar a pensar no sujeito pedagógico surdo. Desde o início, a escolha por esse "segmento" se deu em função de que a escola vem sendo privilegiadamente um espaço de instituição de subjetividades e de modos de vida. Com isso, a escola de surdos, que exerce essa função como qualquer outra escola, é buscada incessantemente pela comunidade surda, a fim de que a construção de subjetividades desenvolvida na escola de surdos possa se dar também de modo a garantir o que quer a comunidade. Os excertos e as questões abordadas neste artigo foram escolhidos no intuito de ilustrar a forma como a comunidade entende a escola como possibilidade de manutenção do seu funcionamento e de seus preceitos. Muito disso se deve ao fato de que o sujeito que é pedagogizado na escola aprende lá a ser político e a dar conta do que quer a comunidade. 


\section{REFERÊNCIAS}

BAUMAN, Zygmunt. Comunidade: a busca por segurança no mundo atual. Rio de Janeiro, RJ: Jorge Zahar, 2003.

. Modernidade líquida. Rio de Janeiro, RJ: Jorge Zahar, 2001.

ESPOSITO, Roberto. Comunidad, inmunidad y biopolítica. Espanha: Herder, 2009.

FENDLER, Lynn. ¿Qué es imposible pensar? Una genealogia del sujeto educado. In: POPKEWITZ, Thomas; BRENNAN, Marie. (Org.). El desafio de Foucault: discurso, conocimiento y poder en la educación. Barcelona: Corredor, 2000. p. 55-80.

GADELHA, Sylvio. Biopolítica, governamentalidade e educação: introduções e conexões, a partir de Michel Foucault. Belo Horizonte: Autêntica, 2009.

GOMES, A. P. G. Simulacro cultural na produção da alteridade surda: recorrências discursivas em contextos de educação de surdos. In: CONGRESSO INTERNACIONAL DE EDUCAÇÃO, 6., 2009, São Leopoldo. Anais... São Leopoldo: 2009. CD-ROM.

ROSE, Nikolas. The death of the social? Re-figuring the territory of government. Economy an society. London: Routledge, v. 25, n. 3, p. 327-356, aug. 1996.

SILVA, Tomaz Tadeu. Dr. Nietzsche, curriculista - com uma pequena ajuda do professor Deleuze. In: MOREIRA, Antonio Flavio Barbosa; MACEDO, Elizabeth Fernandes. (Org.). Currículo, práticas pedagógicas e identidades. Porto: Porto Editora, 2002 p. 35-52. 